\title{
The readability and reliability of Greek web-based information on rhinoplasty*
}

\author{
Dionisios Klonaris', Alexander Karatzanis', Maria Doulaptsi', Maria-Eleni \\ Parakatselaki², Nikolaos Chatzakis', Emmanuel Prokopakis' \\ 'University Hospital of Heraklion, Department of Otorhinolaryngology - Head and Neck Surgery, Panepistimiou Avenue, \\ Heraklion, Crete, Greece \\ 2 University of Crete, Department of Biology, Voutes University Campus, Voutes, Heraklion, Crete, Greece
}

Rhinology Online, Vol 3: 193 - 201, 2020

http://doi.org/10.4193/RHINOL/20.071

*Received for publication:

September 16, 2020

Accepted: October 26, 2020

Published: November 21, 2020

\begin{abstract}
Background: A constantly increasing number of patients seek for Internet sources on diseases or surgical operations before consulting with a medical specialist. Popular among surgical procedures is rhinoplasty. Depending on the quality of information, patient decision making, expectations and satisfaction may be affected in a positive or negative manner. The aim of this study is to objectively assess the readability and reliability of Internet health information in the Greek language on rhinoplasty.
\end{abstract}

Materials and Methods: We performed a search in the Google engine using a combination of Greek language terms relating to rhinoplasty. After collation and rejection of duplicate, irrelevant or invalid links, the first twenty highest ranking Greek Web sites were analyzed using the on-line Greek Language Centre Literacy Level calculator, the on-line Greek text readability calculator, and the DISCERN publication quality assessment instrument.

Results: From the twenty Web sites, 40\% required very good and 35\% required excellent Greek Language Literacy Level for comprehension. Content reading was considered quite difficult in 15\%, difficult in $60 \%$ and very difficult in $25 \%$ of the Web sites. The quality of the Web sites appraised by the DISCERN instrument was low to medium. No correlation was found between Google site rank and DISCERN total score.

Conclusions: In general, the reliability of Internet health information in the Greek language on rhinoplasty is mediocre at best and the readability of the respective texts is lower than recommended. Patients should be cautious and always consult one or more medical specialists before reaching a final decision. Evaluation and accreditation of Internet health information sites would greatly assist on sound patient decision-making and satisfaction.

Key words: rhinoplasty, nose job, nose plastic surgery, health information, Internet, World Wide Web

\section{Introduction}

In recent decades, Internet access world-wide has increased dramatically and the continuously expanding volume of Internet health-related materials has become a prominent source of information ${ }^{(1,2)}$. This phenomenon may have beneficial or detrimental effects on health consumers ${ }^{(3-8)}$ and the readability and reliability of such sources have emerged as central issues in patient education ${ }^{(9)}$. Many tools have been developed for the objective assessment of the quality of this information ${ }^{(10-12)}$ and multiple tests are available for the objective assessment of the readability of texts of any content ${ }^{(13-16)}$. The ever expanding volume of Internet information is indexed by specialized search engines ${ }^{(17-19)}$. Web site ranking algorithms ${ }^{(20)}$ and behavioral traits of information seekers ${ }^{(21)}$ introduce major concerns on the way Internet health-related materials are made available to the patients.

Rhinoplasty is one of the most popular cosmetic procedures in the USA ${ }^{(22)}$ and in Greece. The aim of this study is to objectively assess the readability and reliability of Web-based health information in the Greek language on rhinoplasty. The results 
may provide an insight on the quality of information available to the public and promote an active appraisal of such Web-based Internet sources. To our knowledge, this is the first domestic study aiming to assess the quality of Internet health information in the Greek language on rhinoplasty.

\section{Materials and methods}

Data collection

In July 2020, we performed a Google search for the following

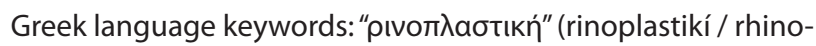

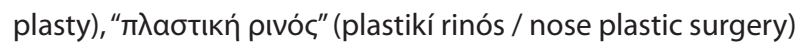

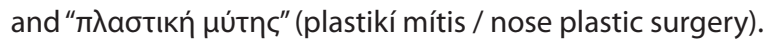

Each term was entered consecutively using default settings on the Firefox v78.0.1 ${ }^{(23)}$ Web browser software. After exclusion of duplicate or invalid links, forum or news groups, advertisements, social media pages, journal articles and video- or audio-only links, we selected the first 20 pertinent individual sites for each keyword search. For each of the three searches, the Web sites received a rank score (20: highest/first, 1: lowest/last). The collation of the combined search results produced 27 individual sites. The cumulative rank score was calculated for each one of them and the 20 highest ranking were selected for further analysis.

The pure body text of each Web site was extracted, removing any programming or formatting computer code (e.g. HTML), advertisements, links or other irrelevant content. The LibreOffice Writer v6.4.5 (24) with Greek language support word processor software was used for hyphenation removal and grammar checking.

\section{Greek Language Literacy Level}

The Centre for the Greek Language ${ }^{(25)}$ provides a free on-line readability and literacy level calculator. The definitions of Greek Language Literacy Levels are shown in Table 1. Level A1 is suitable for children 8-12 years old, while level $\Gamma 2$ requires excellent language knowledge ("mastery") (26). The cleaned-up body text of each Web site was entered and the corresponding literacy level required to comprehend it was calculated.

\section{The Flesch-Kincaid index}

The free on-line Greek text readability tool(27) was used to calculate the Flesch-Kincaid index (FKI) adapted for the Greek language by entering the cleaned-up body text of each Web site. The index score ranges and the corresponding reading ease are shown in Table 2. Scores ranging from 90 to 100 are suitable for 11-year-old students, while texts with scores under 30 are best understood by university graduates ${ }^{(28)}$.

\section{The DISCERN instrument}

The DISCERN instrument ${ }^{(10)}$ was used to evaluate the quality of information of each of the twenty Web sites. It is a 15-item questionnaire with a 5-point scale (1: No, 2: Mostly No, 3: Par-
Table 1. Greek Language Literacy Levels.

\begin{tabular}{|ll}
\hline Level & Description \\
\hline A1 & For children 8-12 years old \\
\hline A2 & Basic knowledge \\
\hline B1 & Moderate knowledge \\
B2 & Good knowledge \\
Г1 & Very good knowledge \\
Г2 & Excellent knowledge \\
\hline
\end{tabular}

Table 2. Flesch-Kincaid index and reading ease.

\begin{tabular}{|ll|}
\hline Flesch-Kincaid index score & Reading ease \\
\hline $100-90$ & Very easy \\
\hline $90-80$ & Easy \\
\hline $80-70$ & Quite easy \\
\hline $70-60$ & Moderate \\
\hline $60-50$ & Quite difficult \\
\hline $50-30$ & Difficult \\
\hline $30-0$ & Very difficult \\
\hline
\end{tabular}

tially, 4: Mostly Yes, 5: Yes) and total score range from 15 to 75. Questions 1 to 8 aim to appraise the reliability of the publication (minimum/maximum sub-score: 8/40), while questions 9 to 15 evaluate the completeness of treatment choices described or offered (minimum/maximum sub-score: 7/35). Item 16 is used to rate the overall quality of the publication, based on the answers to questions 1-15 (1: Low, 2: Mostly Low, 3: Moderate, 4: Mostly High, 5: High).

The twenty Web sites were independently reviewed and evaluated by two ENT Consultants (DK and MD). Reviewer differences in DISCERN scores were discussed and attempt was made to reach a rating consensus. In cases of disagreement, the pertinent Web sites were referred to the Senior ENT Consultants (AK and EP) for the final evaluation verdict.

\section{Statistical analysis}

Statistical analyses were performed using the JASP v0.13(29) open-source statistics software. Frequencies, ranges, means, population standard deviations (PSTDEV) and 95\% confidence intervals $(\mathrm{Cl})$ were calculated. Spearman's rank correlation coefficient was also calculated. Statistical significance was regarded for $p$-value $\leq 0.05$. The LibreOffice Calc v6.4.5 $5^{(24)}$ spreadsheet software was used for graph and chart creation.

\section{Results}

Greek Language Literacy Level

None of the Web sites was suitable for children 8-12 years old, 


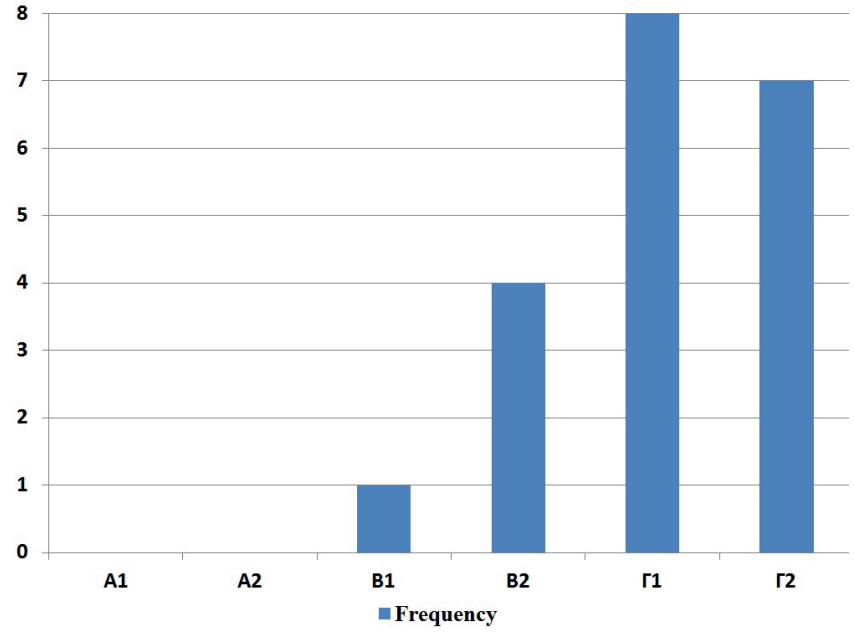

Figure 1. Greek Language Literacy Level frequency column chart.

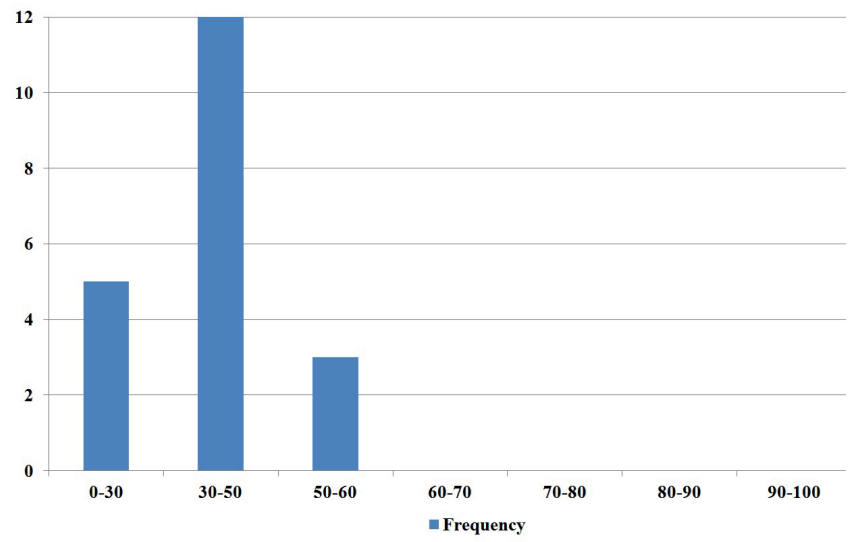

Figure 2. Flesch-Kincaid reading ease level frequencies.

only one (5\%) required moderate knowledge and four (20\%) required good knowledge of the Greek language. Most of the sites required very good $(n=8,40 \%)$ or excellent $(n=7,35 \%)$ literacy level for comprehension. Figure 1 summarizes these findings.

\section{Flesch-Kincaid index and reading ease}

The FKI for all Web sites ranged from 16.81 to 56.57 (mean $=36.50,95 \% \mathrm{Cl}=4.60$ ) and PSTDEV was 10.50. None of the Web sites had the recommended ( $F K I=90-100)$ readability level and all of them were considered quite difficult $(n=3,15 \%)$, difficult $(n=12,60 \%)$ or very difficult $(n=5,25 \%)$ to comprehend. Figure 2 summarizes the findings for the FKI reading ease levels.

\section{Reliability assessment with the DISCERN instrument} The DISCERN scores for all Web sites were low to medium, ranged from 25 to 49 ( mean $=35.10,95 \% \mathrm{Cl}=2.49$ ) and PSTDEV was 5.67. The reliability sub-scores were also mediocre at best, ranging from 14 to 27 (mean $=18.80,95 \% \mathrm{Cl}=1.53$ ) with PST$\mathrm{DEV}=3.49$. Also, the treatment options sub-scores were sub-par, ranging from 10 to 22 (mean $=16.30,95 \% \mathrm{Cl}=1.14$ ) with PST-
Table 3. DISCERN questions descriptive statistics summary.

\begin{tabular}{lcccc}
\hline DISCERN & Range & Mean & $95 \%$ CI & PSTDEV \\
\hline Aim clarity & $3-5$ & 3.95 & 0.17 & 0.38 \\
\hline Aim achievement & $2-5$ & 3.60 & 0.29 & 0.66 \\
\hline Relevance & $2-4$ & 3.60 & 0.26 & 0.58 \\
\hline Information sources clarity & $1-3$ & 1.40 & 0.29 & 0.66 \\
\hline Information sources date & $1-4$ & 1.75 & 0.44 & 0.99 \\
\hline Balance and bias & $1-3$ & 1.40 & 0.29 & 0.66 \\
\hline Additional sources & $1-3$ & 1.35 & 0.25 & 0.57 \\
\hline Areas of uncertainty & $1-3$ & 1.75 & 0.34 & 0.77 \\
\hline Reliability sub-scores & $14-27$ & 18.80 & 1.53 & 3.49 \\
\hline Treatments description & $2-4$ & 3.60 & 0.29 & 0.66 \\
\hline Treatments benefits & $1-4$ & 3.40 & 0.32 & 0.73 \\
\hline Treatments risks & $1-4$ & 2.30 & 0.39 & 0.90 \\
\hline Effects of no treatment & $1-3$ & 1.35 & 0.25 & 0.57 \\
\hline $\begin{array}{l}\text { Treatments and quality } \\
\text { of life }\end{array}$ & $1-4$ & 2.75 & 0.36 & 0.83 \\
\hline Treatment options clarity & $1-3$ & 1.60 & 0.29 & 0.66 \\
\hline Shared decision-making & $1-3$ & 1.30 & 0.24 & 0.56 \\
\hline Treatment options sub- & $10-22$ & 16.30 & 1.14 & 2.61 \\
\hline scores & $25-49$ & 35.10 & 2.49 & 5.67 \\
\hline Total reliability scores & $2-3$ & 2.55 & 0.22 & 0.50 \\
\hline Overall quality scores & & & & \\
\hline
\end{tabular}

$\mathrm{DEV}=2.61$. The overall quality scores of the Web sites were low to medium, ranged from 2 to 3 (mean $=2.55,95 \% \mathrm{Cl}=0.22$ ) with PSTDEV $=0.50$. Table 3 summarizes the descriptive statistics for all the DISCERN questions. DISCERN total scores and sub-scores for each Web site are shown in Figure 3.

\section{Correlation statistics}

No correlation was found between Google site rank and Greek Language Literacy Level (Spearman's $\rho=0.250, P=0.288$ ). Site rank was also not associated with the Flesch-Kincaid index (Spearman's $\rho=-0.027, \mathrm{P}=0.911$ ) or the Flesch-Kincaid reading ease level (Spearman's $\rho=-0.011, P=0.963$ ). Also, no correlation was found between Google site rank and DISCERN publication reliability (Spearman's $\rho=0.173, P=0.466$ ), treatment options (Spearman's $\rho=0.028, P=0.906)$, total (Spearman's $\rho=0.138$, $\mathrm{P}=0.560$ ) or overall quality (Spearman's $\rho=-0.096, \mathrm{P}=0.688$ ) scores.

Additionally, Greek Language Literacy Level showed no association with DISCERN publication total (Spearman's $\rho=0.328$, $\mathrm{P}=0.158$ ) or overall quality (Spearman's $\rho=0.083, \mathrm{P}=0.727$ ) scores. Furthermore, no correlation was found between the Flesch-Kincaid reading ease level and DISCERN publication total (Spearman's $\rho=0.135, \mathrm{P}=0.570$ ) or overall quality (Spearman's $\rho=0.308, P=0.186$ ) scores. Notably, a strong correlation was found between the DISCERN reliability and treatment options 


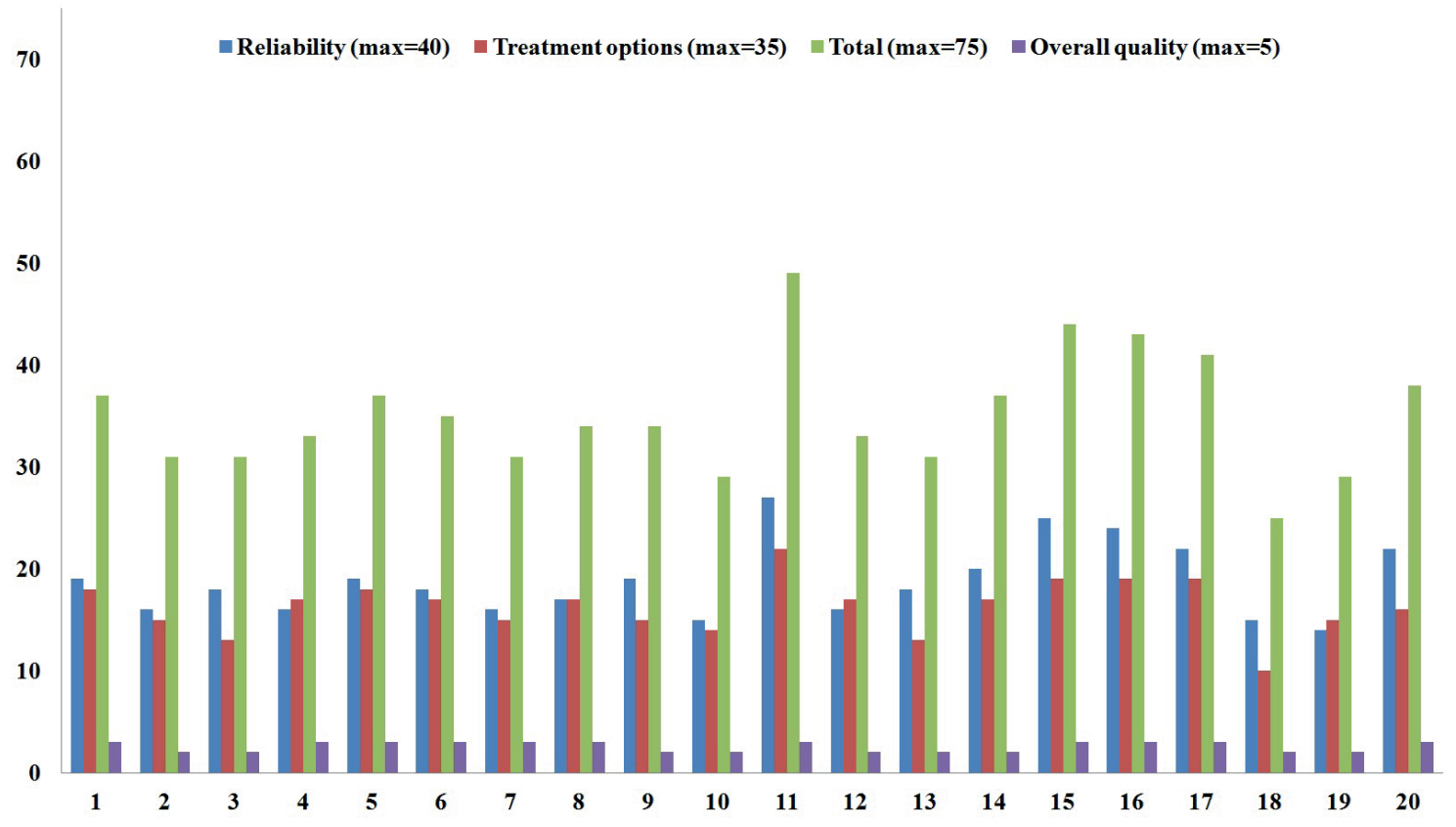

Figure 3. DISCERN total scores and sub-scores per Web site.

Table 4. Correlation statistics summary.

\begin{tabular}{|c|c|c|c|}
\hline & & $\begin{array}{l}\text { Spear- } \\
\text { man's } \rho\end{array}$ & $\mathbf{P}$ \\
\hline \multirow[t]{7}{*}{$\begin{array}{l}\text { Google site } \\
\text { rank }\end{array}$} & $\begin{array}{l}\text { Greek Language Literacy } \\
\text { Level }\end{array}$ & 0.250 & 0.288 \\
\hline & Flesch-Kincaid index & -0.027 & 0.911 \\
\hline & Flesch Kincaid reading ease & -0.011 & 0.963 \\
\hline & DISCERN reliability score & 0.173 & 0.466 \\
\hline & $\begin{array}{l}\text { DISCERN treatment options } \\
\text { score }\end{array}$ & 0.028 & 0.906 \\
\hline & DISCERN total score & 0.138 & 0.560 \\
\hline & $\begin{array}{l}\text { DISCERN overall quality } \\
\text { score }\end{array}$ & -0.096 & 0.688 \\
\hline \multirow{2}{*}{$\begin{array}{l}\text { Greek Langu- } \\
\text { age Literacy } \\
\text { Level }\end{array}$} & DISCERN total score & 0.328 & 0.158 \\
\hline & $\begin{array}{l}\text { DISCERN overall quality } \\
\text { score }\end{array}$ & 0.083 & 0.727 \\
\hline \multirow{2}{*}{$\begin{array}{l}\text { Flesch-Kincaid } \\
\text { reading ease }\end{array}$} & DISCERN total score & 0.135 & 0.570 \\
\hline & $\begin{array}{l}\text { DISCERN overall quality } \\
\text { score }\end{array}$ & 0.308 & 0.186 \\
\hline $\begin{array}{l}\text { DISCERN relia- } \\
\text { bility score }\end{array}$ & $\begin{array}{l}\text { DISCERN treatment options } \\
\text { score }\end{array}$ & 0.710 & $<.001$ \\
\hline
\end{tabular}

scores (Spearman's $\rho=0.710, P<0.001)$.

Correlation statistics are summarized in Table 4.

Purpose, specialty initiatives, information providers and Web site design

Eighty percent $(n=16)$ of the twenty collated Web sites were focused on health service advertisements, while only $20 \%(n=4)$ aimed for pure patient education. The initiative to provide this information was mainly from Plastic Surgeons $(65 \%, n=13)$, followed by Otorhinolaryngologists $(30 \%, n=6)$. Also, the vast majority $(80 \%, n=16)$ of the information providers were Private Practice Medical Centers or Doctors, occupying the first 14 highest ranking positions. Table 5 summarizes these findings. While we had no means to objectively evaluate the functionality and aesthetics of the collated Greek Web sites, most of them appeared well designed and easily navigated, with plenty of pictures and patient photos. Figure 4 assembles the home pages of the four highest ranking Web Sites.

\section{Discussion}

In recent decades, the evolution of computer hardware and the continuous development of software have provided free availability and ease of access to all kinds of information. This phenomenon is greatly pronounced on the volume of Internet health-related materials, which have become a prominent source of health information ${ }^{(1,2)}$, to the extent that Broadband Internet Access has become a social determinant of health ${ }^{(30)}$. On the other hand, socio-demographic factors may pose access barriers to such sources for certain populations (the "digital divide") ${ }^{(31,32)}$. Removal of these barriers to strictly medical knowledge has redefined medical practice and many aspects of the classic doctor-patient relationship ${ }^{(33-35)}$. Also, Health Information Portals have increased their content and service functions ${ }^{(36)}$. The evolution of mobile technologies now offers ease of access to such sources and utilities not available previously ${ }^{(37,38)}$. Additionally, the number of Internet health information seekers continually increases over time, as it has been reported by numerous 
Table 5. Purpose, specialty initiatives and information providers.

\begin{tabular}{|c|c|c|c|}
\hline Rank & Purpose & Specialty & Provider \\
\hline 1 & Service Advertisement & ENT & Private Practice ENT Surgeon \\
\hline 2 & Service Advertisement & Plastic Surgery & Private Medical Center \\
\hline 3 & Service Advertisement & Plastic Surgery & Private Practice Plastic Surgeon \\
\hline 4 & Service Advertisement & ENT & Private Practice ENT Surgeon \\
\hline 5 & Service Advertisement & Plastic Surgery & Private Practice Plastic Surgeon \\
\hline 6 & Service Advertisement & Plastic Surgery & Private Medical Center \\
\hline 7 & Service Advertisement & Plastic Surgery & Private Practice Plastic Surgeon \\
\hline 8 & Service Advertisement & ENT & Private Practice ENT Surgeon \\
\hline 9 & Service Advertisement & Plastic Surgery & Private Practice Plastic Surgeon \\
\hline 10 & Service Advertisement & Plastic Surgery & Private Practice Plastic Surgeon \\
\hline 11 & Service Advertisement & ENT & Private Medical Center \\
\hline 12 & Service Advertisement & Plastic Surgery & Private Practice Plastic Surgeon \\
\hline 13 & Service Advertisement & ENT & Private Medical Center \\
\hline 14 & Service Advertisement & Plastic Surgery & Private Practice Plastic Surgeon \\
\hline 15 & Patient Education & ENT & Health Information Provider \\
\hline 16 & Service Advertisement & Plastic Surgery & Health Information Provider \\
\hline 17 & Patient Education & None & On-line Encyclopedia \\
\hline 18 & Service Advertisement & Plastic Surgery & Private Practice Plastic Surgeon \\
\hline 19 & Patient Education & Plastic Surgery & Health Information Provider \\
\hline 20 & Patient Education & Plastic Surgery & Health Information Provider \\
\hline
\end{tabular}

studies worldwide ${ }^{(39-42)}$. This trend is especially prevalent among patients interested in aesthetic procedures, including rhinoplasty ${ }^{(43,44)}$. These developments have introduced new benefits as well as new challenges in the doctor-patient interaction ${ }^{(33-35)}$. The DISCERN instrument is a popular questionnaire-based validated tool focusing on the overall quality of health-related internet sites ${ }^{(10)}$. Emerging machine-based learning technologies offer the prospect of automated assessment of Web sites using the DISCERN ${ }^{(11)}$. The LIDA is another appraisal instrument that allows objective measurements of the accessibility, usability and reliability of Internet health information sites ${ }^{(12)}$. Health-related educational materials available to the public should be of high quality. High reliability of such information has been shown to be beneficial to patients and information seekers, while intentional or unintentional quality compromises have detrimental effects ${ }^{(45)}$. Understanding the quality of Internet health information in the digital era is of paramount importance ${ }^{(46)}$.

Guiraud's R index is a measure of lexical diversity and richness ${ }^{(13)}$. Reading ease can be evaluated based on the scores of such measures as the Flesch-Kincaid ${ }^{(14)}$ and the Gunning Fog indi$\operatorname{ces}^{(15)}$. In the USA, the recommended readability level of patient health information and educational materials should be suitable for 11-13 years old children ${ }^{(16)}$ and equally profit subjects with different eHealth literacy levels $s^{(47)}$. In Greece, on the other hand, there are no official recommendations for such materials. Com- prehension challenges may negatively affect patient decisionmaking, participation and satisfaction of treatment ${ }^{(48)}$.

The Web search engines are the most popular method employed for Internet information retrieval. Google is the most popular search engine in Greece, accounting for a market share of about $98 \%{ }^{(49)}$. These software systems use a Web crawler approach ${ }^{(50)}$ to gather results from Internet sources. Complex algorithms are used for Web site ranking, although the visibility of a specific Internet page may be increased ("optimized") by paid placement, irrelevant of its quality or popularity ${ }^{(20)}$. There is much controversy concerning the site ranking criteria; reliability and relevance are not the sole determinants and the displayed results may be highly biased ${ }^{(51)}$. One the other hand, while each query may return hundreds to thousands of results, patients tend to visit only the first ten highest ranking Web sites ${ }^{(21)}$. Under this scope, such a behavioral trait may affect in indeterminate ways patient exposure and interaction with health-related material published in the Web. Therefore, a major concern exists on the way Internet health information is made available to the patients. Although no pooled data exist in Greece, augmentation rhinoplasty is the most frequently performed aesthetic operation by Otorhinolaryngologists. Another indication for this procedure is nasal valve function restoration, which may improve disease-specific quality of life $\mathrm{e}^{(52,53)}$. Rhinoplasty procedures offer a number of alternative actions to both patients and physicians. 


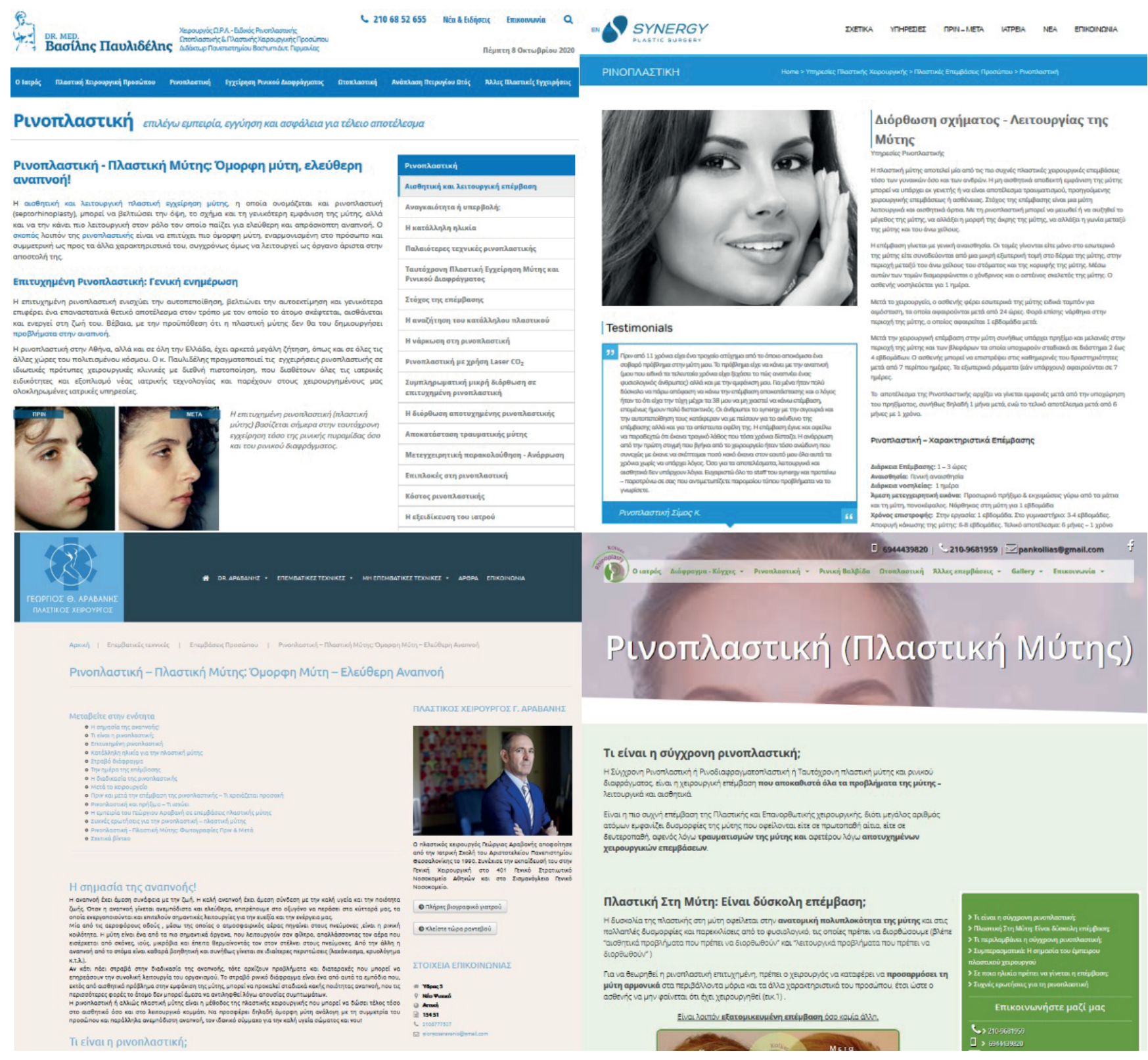

Figure 4. Home page assembly of the four highest ranking Greek Web sites on Rhinoplasty.

The doctor-patient interaction very often involves a debate about facial symmetry, surgery perspectives, as well as patient satisfaction ${ }^{(54)}$. Notably, the high prevalence of body dysmorphic disorder reported in patients seeking rhinoplasty appears to have a negative impact on subjective treatment outcomes ${ }^{(55,56)}$. Although one of the most challenging procedures in plastic surgery ${ }^{(57)}$, it has a high safety profile and low complication rates ${ }^{(58)}$. On the other hand, the relatively low satisfaction rates reported may be due to potentially unrealistic patient expectations ${ }^{(59)}$. This finding underlines the importance of sound patient counseling and high quality health information availability, including Web-based Internet sources.

It has been shown by numerous studies that ample health information availability may offer additional social and emotional support to health consumers( ${ }^{(3)}$, better disease prevention and management ${ }^{(4)}$, reduced anxiety ${ }^{(5)}$, and greater self-reliance ${ }^{(6,7)}$. On the other hand, the uncontrolled and unfiltered publication of such materials may result in patient misinformation or hazards, if unreliable or incorrect ${ }^{(8)}$. As the Internet has become a prominent source of health information, the readability and reliability of the latter have emerged as central issues in patient education ${ }^{(9)}$. The quality of online health information has been assessed by a large number of studies ${ }^{(45,60-63)}$. In general, it is mediocre at best and of low standards. To amend this, independent foundations or other entities provide certification services for medical and health Web sites ${ }^{(64,65)}$. Numerous studies have assessed the reading ease of publications on ENT health conditions ${ }^{(66-68)}$ and procedures ${ }^{(45,69-71)}$. In general, the readability 
of Internet health information is considered low and does not adhere to literacy level recommendations.

To the authors' knowledge, this is the first domestic study aiming to assess the quality of Greek Web-based health information on rhinoplasty. Our results revealed low readability and low to moderate reliability of the screened Greek Web sites, which is in line with publications in other languages and countries in Europe and across the globe ${ }^{(44,45)}$. The overall quality of Internet health information in the Greek language is sub-par, which may negatively affect patient decision-making, expectations and satisfaction. Certification of Greek Web sites containing health information and patient educational material remains an unmet need. Limitations of our study include the limited reference time-frame (July 2020), the non-exhaustive search for Internet health information sources (e.g. exclusion of news groups, social media pages or multimedia sites) and the narrow spectrum of the used Google search keywords.

\section{Conclusions}

In general, the reliability of Internet health information on rhinoplasty is below average and the readability of the respective texts is lower than recommended. Greek Web sites on rhinoplasty are also of low to moderate quality and require high literacy levels to comprehend. Patients should be cautious and always consult one or more medical specialists before reaching a final decision. Certification of Internet health information sites using objective appraisal tools would greatly assist on sound patient decision-making and satisfaction.

\section{Acknowledgments}

None.

\section{Authorship contribution}

Conceptualization, AK and NC; methodology, DK, NC and MD; software, DK and M-EP; validation, AK and EP; formal analysis, $M-E P$; data curation, M-EP; writing - original draft preparation, DK; writing — review and editing, AK, MD and EP; supervision, AK All authors have read and agreed to the published version of the manuscript.

\section{Conflict of interest}

None to declare.

\section{Funding}

None to declare.

\section{Consent for publication}

Not applicable.

\section{Availability of data and materials}

Not applicable.

\section{References}

1. Frisse, M.E.; Kelly, E.A.; Metcalfe, E.S. An Internet primer: resources and responsibilities. Acad Med 1994, 69, 20-24.

2. Utter, J.; Lucassen, M.; Denny, S.; Fleming, T.; Peiris-John, R.; Clark, T. Using the Internet to access health-related information: results from a nationally representative sample of New Zealand secondary school students. Int J Adolesc Med Health 2017, doi:10.1515/ ijamh-2017-0096.

3. Zhao, Y.; Zhang, J. Consumer health information seeking in social media: a literature review. Health Info Libr J 2017, 34, 268-283.

4. Rogers, M.A.; Lemmen, K.; Kramer, R.; Mann J.; Chopra, V. Internet-Delivered Health Interventions That Work: Systematic Review of Meta-Analyses and Evaluation of Website Availability. J. Med. Internet Res. 2017, 19, e90.

5. Gustafson, D.H.; Hawkins, R.P.; Boberg, E.W. McTavish, F.; Owens, B.; Wise, M.; Berhe, $H_{\text {.; }}$ Pingree, S. CHESS: 10 years of research and development in consumer health informat ics for broad populations, including the underserved. Int J Med Inform 2002, 65 169-177.

6. Wathen, C.N.; Harris, R.M. "I try to take care of it myself." how rural women search for health information. Qual Health Res 2007, 17,639-651,
7. Griffiths, K.M.; Christensen, H. Internetbased mental health programs: a powerful tool in the rural medical kit. Aust J Rural Health 2007, 15, 81-87,

8. Daraz, L.; Morrow, A.S.; Ponce, O.J.; Beuschel, B.; Farah, M.H.; Katabi, A.; Alsawas, M.; Majzoub, A.M.; Benkhadra, R.; Seisa, M.O. et al. Can Patients Trust Online Health Information? A Meta-narrative Systematic Review Addressing the Quality of Health Information on the Internet. J Gen Intern Med 2019,

9. Beaunoyer, E.; Arsenault, M.; Lomanowska, A.M.; Guitton, M.J. Understanding online health information: Evaluation, tools, and strategies. Patient Educ Couns 2017, 100 183-189.

10. 10. Charnock, D.; Shepperd, S. Needham, G.; Gann, R. DISCERN: an instrument for judging the quality of written consumer health information on treatment choices. J Epidemiol Community Health 1999, 53, 105-111.

11. Allam, A.; Schulz, P.J.; Krauthammer, M. Toward automated assessment of health Web page quality using the DISCERN instrument. J Am Med Inform Assoc 2017, 24, 481-487.

12. André Tomlin Full LIDA tool (v1.2 Copyright Minervation 2007, PDF).

13. Hout, R.; Vermeer, A. Comparing measures of lexical richness. In: H. Daller, J. Milton \& J. Treffers-Daller (eds.), Modelling and assessing vocabulary knowledge (93-116). Cambridge: Cambridge University Press. 2007.

14. Kincaid, J.; Fishburne, R.; Rogers, R.; Chissom, B. Derivation Of New Readability Formulas (Automated Readability Index, Fog Count And Flesch Reading Ease Formula) For Navy Enlisted Personnel. Institute for Simulation and Training 1975.

15. Gunning, R. The technique of clear writing.; McGraw-Hill: Toronto, 1952;

16. Cotugna, N.; Vickery, C.E.; Carpenter-Haefele, K.M. Evaluation of literacy level of patient education pages in health-related journals. J Community Health 2005, 30, 213-219.

17. Google Available online: http://www.google.com (accessed on Jul 6, 2020).

18. Yahoo Available online: http://www.yahoo. com (accessed on Jul 6, 2020).

19. Bing Available online: http://www.bing.com (accessed on Jul 6, 2020).

20. Search engine optimization. Wikipedia 2020.

21. Eysenbach, G.; Köhler, C. How do consumers search for and appraise health information on the world wide web? Qualitative study using focus groups, usability tests, and in-depth interviews. BMJ 2002, 324, 573-577. 
22. Hopkins, Z.H.; Moreno, C.; Secrest, A.M Influence of Social Media on Cosmetic Procedure Interest. J Clin Aesthet Dermatol 2020, 13, 28-31.

23. Firefox Available online: http://www.mozilla. org (accessed on Jul 7, 2020).

24. LibreOffice Available online: http://www. libreoffice.org/ (accessed on Jul 7, 2020).

25. Centre for the Greek Language Available online: http://www.greek-language.gr (accessed on Jul 7, 2020).

26. Trim, J.L.M.; Council of Europe.; Council for Cultural Co-operation. Some possible lines of development of an overall structure for a European unit/credit scheme for foreign language learning by adults; Council for Cultural Co-operation of the Council of Europe: Strasbourg, 1978.

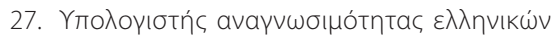

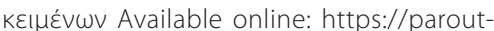
sas.jmc.gr/different/rdblty.php (accessed on Jul 7, 2020).

28. Flesch-Kincaid readability tests - Wikipedia Available online: https://en.wikipedia.org/ wiki/Flesch\%E2\%80\%93Kincaid_readability_tests (accessed on Jul 7, 2020).

29. JASP Available online: http://jasp-stats.org/ (accessed on Jul 7, 2020).

30. Benda, N.C.; Veinot, T.C.; Sieck, C.J.; Ancker, J.S. Broadband Internet Access Is a Social Determinant of Health! Am J Public Health 2020, 110, 1123-1125.

31. Estacio, E.V.; Whittle, R.; Protheroe, J. The digital divide: Examining socio-demographic factors associated with health literacy, access and use of internet to seek health information. J Health Psychol 2017 1359105317695429.

32. McCloud, R.F.; Okechukwu, C.A.; Sorensen, G.; Viswanath, K. Beyond access: barriers to internet health information seeking among the urban poor. J Am Med Inform Assoc 2016, 23, 1053-1059.

33. Coiera, E. The Internet's challenge to health care provision. BMJ 1996, 312, 3-4.

34. Tan, S.S.-L.; Goonawardene, N. Internet Health Information Seeking and the Patient-Physician Relationship: A Systematic Review. J. Med. Internet Res. 2017, 19, e9.

35. Haluza, D.; Naszay, M.; Stockinger, A.; Jungwirth, D. Digital Natives Versus Digital Immigrants: Influence of Online Health Information Seeking on the Doctor-Patient Relationship. Health Commun 2017, 32, 1342-1349.

36. Choi, H.; Lee, S.-K. A Prospective Analysis of Health Information Portals in Four Years. Int J Environ Res Public Health 2020, 17.

37. Solecki, $\mathrm{S}$. The smart use of smartphones in pediatrics. J Pediatr Nurs 2020, 55, 6-9.

38. Seys, S.F.; De Bont, S.; Fokkens, W.J.; Bachert, C.; Alobid, I.; Bernal-Sprekelsen, M.; Bjermer, L.; Callebaut, I.; Cardell, L.-O.; Carrie, S.; et al. Real-life assessment of chronic rhinosinusitis patients using mobile technology: The mySinusitisCoach project by EUFOREA. Allergy 2020.

39. Sturiale, A.i Pata, F.; De Simone, V.i Pellino, G.; Campennì, P.; Moggia, E.; Manigrasso,
M.; Milone, M.; Rizzo, G.; Morganti, R.; et al. Internet and Social Media Use Among Patients with Colorectal Diseases (ISMAEL): A Nationwide Survey. Colorectal Dis 2020.

40. Hills, O.; Shah, D. Online health information seeking, medical care beliefs and timeliness of medical check-ups among African Americans. Patient Educ Couns 2020.

41. Kumar, G.; Garg, A.; Goswami, M.; Rehman, F.; Bidhan, R. Parent's attitude toward use of internet for child's oral health and treatment. J Indian Soc Pedod Prev Dent 2020 38, 110-114.

42. Shen, J.K.; Every, J.; Morrison, S.D. Massenburg, B.B.; Egbert, M.A.; Susarla, S.M Global Interest in Oral and Maxillofacial Surgery: Analysis of Google Trends Data. J. Oral Maxillofac. Surg. 2020.

43. Becker, D.G. Website for rhinoplasty and facial plastic surgery. Facial Plast Surg 2006, 22, 70-74.

44. Szychta, P.; Zieliński, T.; Rykała, J.; Witmanowski, H.; Kruk-Jeromin, J. Role of the internet in communication between patient and surgeon before rhinoplasty. Plast Surg Hand Surg 2012, 46, 248-251.

45. Haymes, A.T. The Quality of Rhinoplasty Health Information on the Internet. Ann Plast Surg 2016, 76, 143-149.

46. Ghezzi, P.; Ford, E. Editorial: Dimensions of Health Information Quality. Front Public Health 2020, 8

47. Reder, M.; Soellner, R.; Kolip, P. Do Women With High eHealth Literacy Profit More From a Decision Aid on Mammography Screening? Testing the Moderation Effect of the eHEALS in a Randomized Controlled Trial. Front Public Health 2019, 7, 46

48. Sharma, A.N.; Martin, B.; Shive, M.; Zachary, C.B. The readability of online patient information about laser resurfacing therapy. Dermatol. Online J. 2020, 26.

49. Search Engine Market Share Greece StatCounter Global Stats Available online: http://gs.statcounter.com/search-enginemarket-share/all/greece (accessed on Ju 6, 2020).

50. Web crawler Available online: http:// en.wikipedia.org/wiki/Web_crawler (accessed on Jul 11, 2020).

51. Web search engine Available online: http:// en.wikipedia.org/wiki/Web_search_engine (accessed on Jul 11, 2020).

52. Kondo, M.; Orgain, C.; Alvarado, R.; Marcells, G.N.; Harvey, R.J. The Effects of Lateral Crural Tensioning with an Articulated Alar Rim Graft Versus Lateral Crural Strut Graft on Nasal Function. Facial Plast Surg Aesthet Med 2020, doi:10.1089/fpsam.2020.0056.

53. 53. Rhee, J.S.; Poetker, D.M.; Smith, T.L.; Bustillo, A.; Burzynski, M.; Davis, R.E. Nasal valve surgery improves disease-specific quality of life. Laryngoscope 2005, 115, 437-440.

54. Prokopakis, E.P.; Vlastos, I.M.; Picavet, V.A.; Nolst Trenite, G.; Thomas, R.; Cingi, C.; Hellings, P.W. The golden ratio in facial symmetry. Rhinology 2013, 51, 18-21.

55. Picavet, V.A.; Prokopakis, E.P.; Gabriëls, L.;
Jorissen, M.; Hellings, P.W. High prevalence of body dysmorphic disorder symptoms in patients seeking rhinoplasty. Plast. Reconstr Surg. 2011, 128, 509-517.

56. Picavet, V.A.; Gabriëls, L.; Grietens, J.; Jorissen, M.; Prokopakis, E.P.; Hellings, P.W. Preoperative symptoms of body dysmorphic disorder determine postoperative satisfaction and quality of life in aesthetic rhinoplasty. Plast. Reconstr. Surg. 2013, 131, 861-868.

57. Rohrich, R.J.; Afrooz, P.N. Primary Open Rhinoplasty. Plast. Reconstr. Surg. 2019, 144 102e-117e.

58. Manhas, P.; Angral, S.; Kotwal, S. Outcome and Pitfalls of Open Rhinoplasty. Indian J Otolaryngol Head Neck Surg 2020, 72, 17-23

59. Khansa, I.; Khansa, L.; Pearson, G.D. Patient Satisfaction After Rhinoplasty: A Social Media Analysis. Aesthet Surg J 2016, 36, NP1-5

60. Biggs, T.C.; Jayakody, N.; Best, K.; King, E.V. Quality of online otolaryngology health information. J Laryngol Otol 2018, 132, 560-563.

61. Horváth, T.; Matics, K.; Meskó, B. [An objective scoring system to evaluate the credibility of health related websites]. Orv Hetil 2018, 159, 511-519.

62. Biggs, T.C.; Bird, J.H.; Harries, P.G.; Salib, R.J. YouTube as a source of information on rhinosinusitis: the good, the bad and the ugly. J Laryngol Otol 2013, 127, 749-754.

63. Alwani, M.M.; Campiti, V.J.; Bandali, E.H. Nesemeier, B.R.; Ting, J.Y.; Shipchandler, T.Z. Evaluation of the Quality of Printed Online Education Materials in Cosmetic Facial Plastic Surgery. Facial Plast Surg Aesthet Med 2020, 22, 255-261.

64. HONcode Available online: http://www. hon.ch/HONcode/ (accessed on Jul 11, 2020).

65. AACl Available online: http://aacihealthcare. com/services/medical-content-certification/ (accessed on Jul 11, 2020).

66. Meyer, M.F.; Bacher, R.; Roth, K.S.; Beutner, D.; Luers, J.C. [Systematic analysis of the readability of patient information on websites of German nonuniversity ENT hospitals]. HNO 2014, 62, 186, 188-192, 194-195.

67. Ritchie, L.; Tornari, C.; Patel, P.M.; Lakhani, R. Glue ear: how good is the information on the World Wide Web? J Laryngol Otol 2016, 130, 157-161.

68. O'Connell Ferster, A.P.; Hu, A. Evaluating the quality and readability of Internet information sources regarding the treatment of swallowing disorders. Ear Nose Throat J 2017, 96, 128-138.

69. Patel, C.R.; Cherla, D.V.; Sanghvi, S.; Baredes, S.; Eloy, J.A. Readability assessment of online thyroid surgery patient education materials. Head Neck 2013, 35, 1421-1425.

70. Wozney, L.; Chorney, J.; Huguet, A.; Song, J.S.; Boss, E.F.; Hong, P. Online Tonsillectomy Resources: Are Parents Getting Consistent and Readable Recommendations? Otolaryngol Head Neck Surg 2017, 156, 
844-852.

71. Santos, P.J.F.; Daar, D.A.; Paydar, K.Z.; Wirth G.A. Readability of Online Materials for Rhinoplasty. World J Plast Surg 2018, 7 89-96.
Emmanuel Prokopakis

University Hospital of Heraklion

Department of Otorhinolaryngology

- Head and Neck Surgery

Panepistimiou Avenue

71110, Heraklion

Crete

Greece

Tel. +302810392347

Cell: +306932237622

E-mail: eprokopakis@gmail.com

ISSN: 2589-5613 / O2020 The Author(s). This work is licensed under a Creative Commons Attribution 4.0 International License. The images or other third party material in this article are included in the article's Creative Commons license, unless indicated otherwise in the credit line; if the material is not included under the Creative Commons license, users will need to obtain permission from the license holder to reproduce the material. To view a copy of this license, visit http://creativecommons.org/ licenses/by/4.0/ 